\section{$\triangle$}

DOMINICAN

U NIVERSITY

\title{
The Rise of Anxiety Among the College Age Population
}

Kaleigh Landberg, Dr. Brett Bayles, Dr. Andria Rusk

Dominican University of California

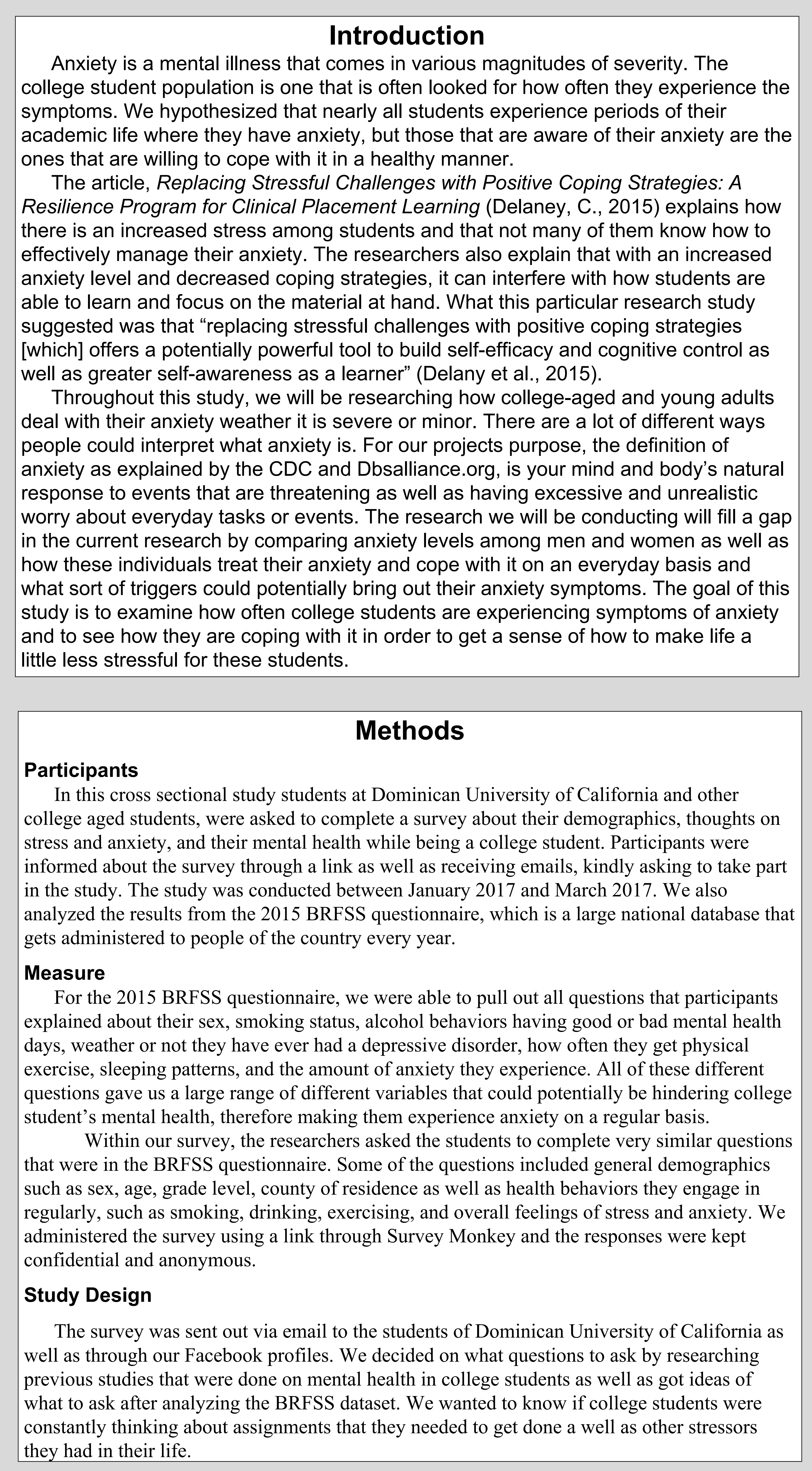

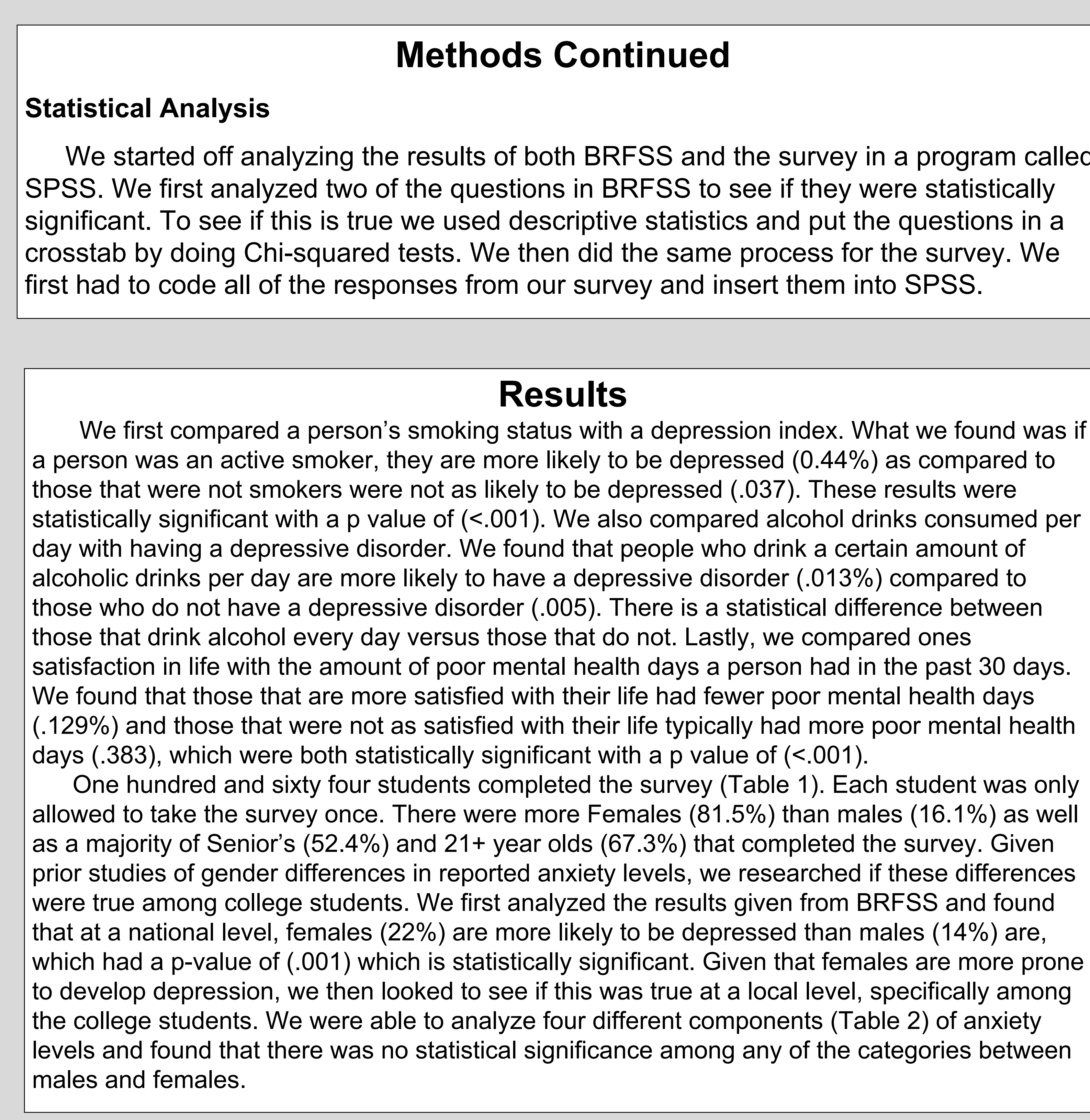

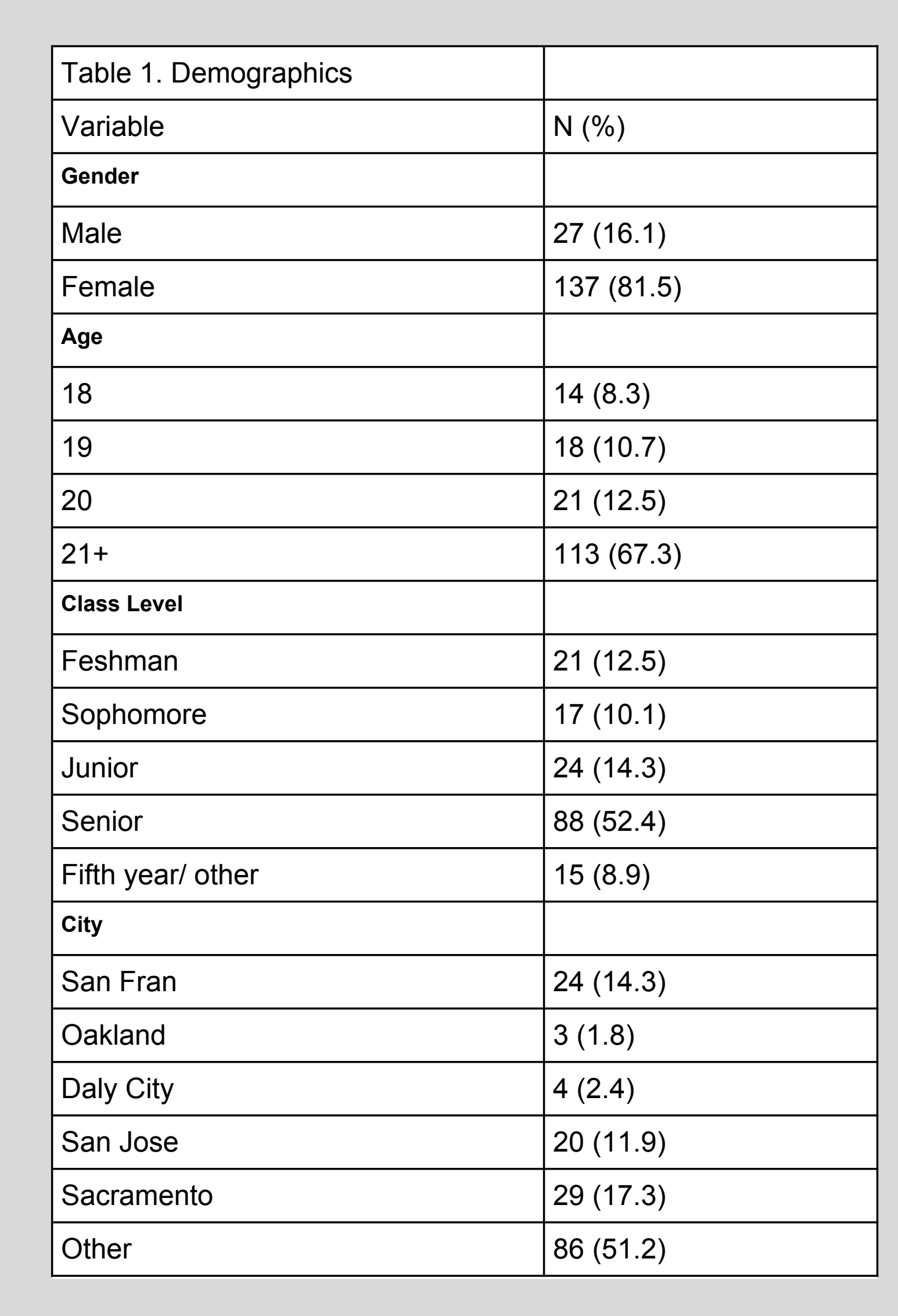

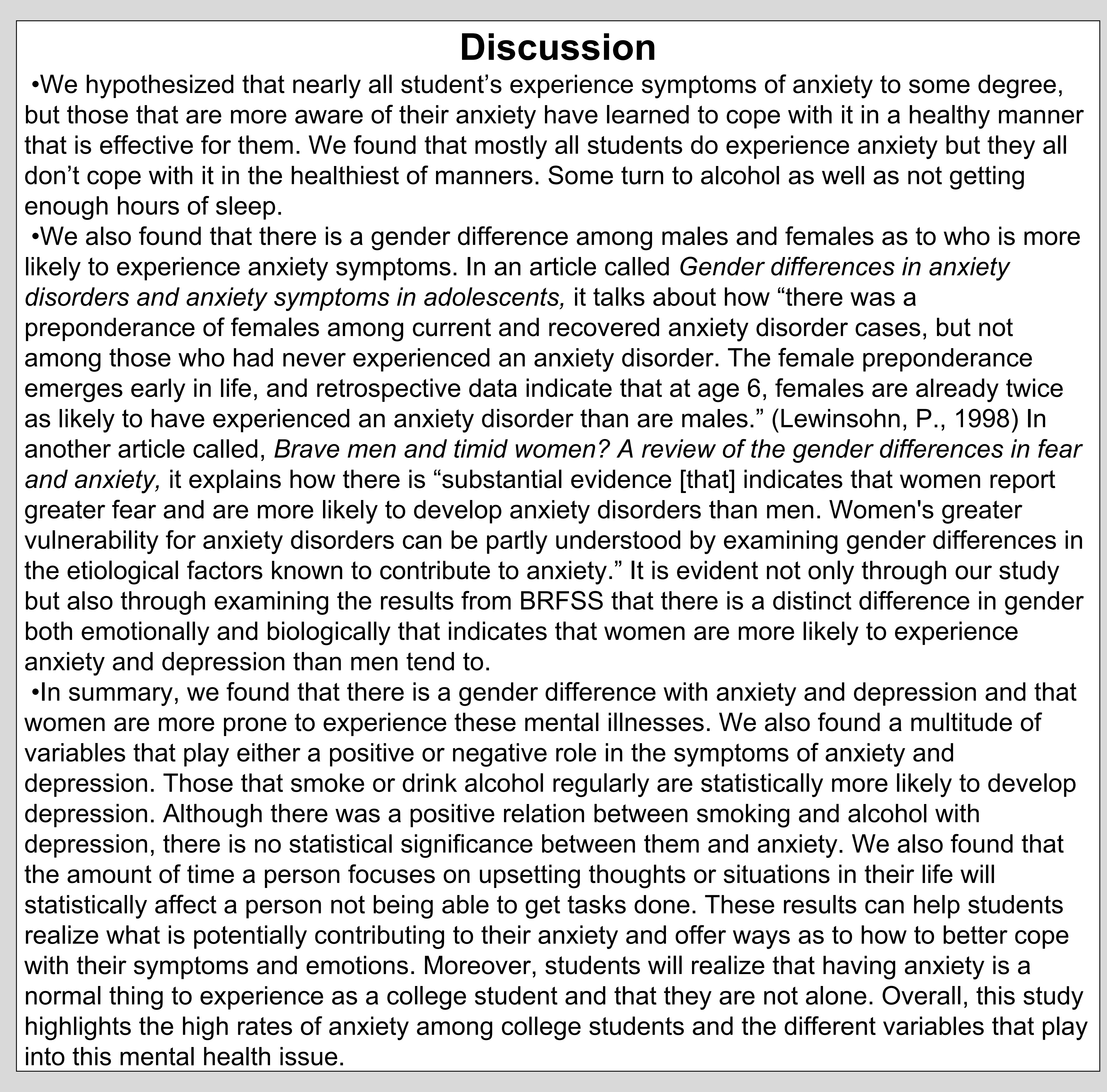
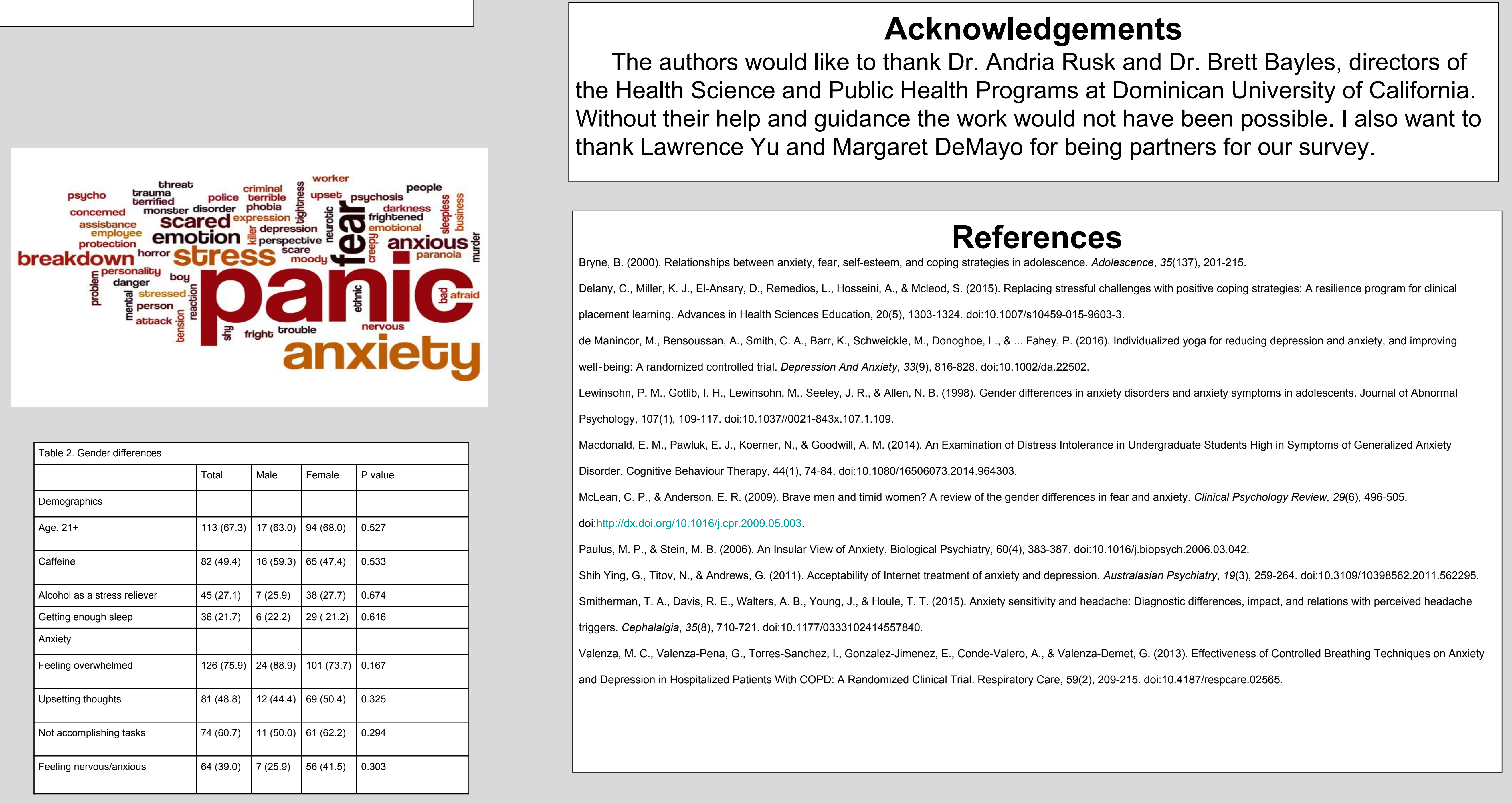